\title{
Environmental life-cycle costing: a code of practice
}

\author{
Thomas E. Swarr • David Hunkeler • Walter Klöpffer • \\ Hanna-Leena Pesonen • Andreas Ciroth • \\ Alan C. Brent • Robert Pagan
}

Received: 6 April 2011 / Accepted: 6 April 2011 /Published online: 27 April 2011

(C) Springer-Verlag 2011

\section{Introduction}

Society of Environmental Toxicology and Chemistry (SETAC) has published a code of practice for environmental life-cycle costing (LCC), which provides a framework for evaluating decisions with consistent, but flexible systems

T. E. Swarr $(\bowtie)$

Sustainability By Design, LLC,

8 Shultas $\mathrm{Pl}$,

Hartford, CT 06114, USA

e-mail: tomswarr@sustainabilitybydesign.org

D. Hunkeler

AQUA+TECH Specialties S.A,

Chemin du Chalet-du-Bac 4,

CH-1283 La Plaine CP 28, Geneva, Switzerland

W. Klöpffer

LCA Consult \& Review,

Am Dachsberg 56E,

60435 Frankfurt am Main, Germany

H.-L. Pesonen

University of Jyväskylä, School of Business and Economics,

P.O. Box 35, 40014 University of Jyväskylä, Finland

A. Ciroth

GreenDeltaTC GmbH,

Raumerstrasse 7 ,

10437 Berlin, Germany

A. C. Brent

School of Public Leadership, Sustainability Institute,

Stellenbosch, Stellenbosch University,

7600 Stellenbosch, South Africa

\section{R. Pagan}

Geography, Planning and Environmental Management,

The University of Queensland,

St Lucia, QLD, Australia boundaries as a component of product sustainability assessments (Swarr et al. 2011). The code of practice builds on an earlier monograph that summarized 3 years of effort by the SETAC-Europe Working Group on LifeCycle Costing (Hunkeler et al. 2008). The code of practice is grounded in a conceptual framework for life-cycle sustainability assessment (LCSA) of products that uses distinct analyses for each of the three pillars of sustainability, environment, economy, and social equity.

$\mathrm{LCSA}=\mathrm{LCA}+\mathrm{LCC}+\mathrm{SLCA}$

Life-cycle assessment (LCA) is the only pillar that has been standardized to date (ISO 2006a, b). UNEP (2009) has published guidelines for social LCAs and is currently developing methodological sheets for impact subcategories. The code of practice reviews historical development of lifecycle methods, outlines the technical requirements and guidelines for LCC, and illustrates various methodological choices with a detailed case study. The objective of the code of practice is to provide readers with a solid understanding of how to apply LCC in parallel with LCA to stimulate additional case studies and peer-reviewed research to further refine the methodology. The ultimate goal is to build consensus for an international standard that parallels the ISO 14040 standard for LCA.

\section{Discussion}

LCC predates LCA, and distinct and different conceptual foundations and methodological approaches can be traced to its developmental roots in systems engineering (Blanchard 1978). There has been limited integration of these methods, although the value of LCC for sustainability assessments has been recognized (Norris 2001; Hunkeler and 
Rebitzer 2003; Klöpffer 2008). Now, the code of practice provides guidance that builds on the four-phase structure of the ISO 14040 standard to facilitate definition and application of consistent system boundaries for complementary LCC and LCA studies of a given product system. Goal and scope definition is similar to that of an LCA. Different parts of the product system may fall below relevant cut-off criteria for the separate LCC and LCA components. For example, the early research and development may impose significant costs but little environmental impact. The key is that both studies refer to a consistent definition of the product system, and that cut-off criteria do not conflict with the intended goal and scope of the study. One aspect that can be challenging is that LCC attempts to capture all costs across the life cycle, and some costs are borne by different actors with very different perspectives of the costs and potentially conflicting goals. Although an LCC is conducted to inform decision making of a particular actor, ideally the data can be presented in a way to fairly inform all actors in the product system.

Another key consideration is to avoid double counting the same environmental impacts in both financial and physical terms. A primary motivation for LCC studies is to fully account for the financial costs of life-cycle environmental aspects and impacts that ultimately result from a decision. This can be achieved by internalizing the costs, namely by applying the polluter pays principle, or by using information to make the impacts visible at the time of the decision. In general, only those costs that are likely to be internalized in the decision- relevant time frame should be monetized. These costs should reflect only real monetary flows that are covered by one or more actors in the product system.

Economic life-cycle inventory faces many of the same data access and quality issues faced in a LCA. Because everyone is familiar with currency units, costs data can create a false sense of certainty (Ciroth 2009). In fact, the cost data will usually come from many different sources and developing a consistent data set for a study can be challenging. In addition, some data may be business sensitive. Different industry sectors have developed customized cost models and terminology that may have to be reconciled in constructing the inventory. Yet, another challenge is that cost data can be more volatile than physical units, and the analyst must exercise caution when updating or smoothing cost data to ensure consistency across the full inventory. Costs data may be gathered in different currencies and reflect different time periods. Thus, the inventory data will need to be restated in a common currency at present value using appropriate exchange and discount rates (Ciroth 2009). Allocation is the process of assigning costs to particular cost objects, and has been a contentious topic in both LCC and LCA literature (Schaltegger and Burrit 2000; Curran 2007). ISO 14040 recommends avoiding allocation by either decomposing the process into equivalent sub-processes or by expanding the system. These operations are not performed in LCC, and extra care may be required to ensure consistent system definition with a LCA that has applied one of these methods. Selection of an appropriate discount rate is dependent on the goal and scope. It is typically based on the opportunity cost of money for the decision maker, but if the focus is on equity or other social goals, such as environmental preservation, then a social discount rate will be more appropriate (Howarth 1996).

There is no comparable impact assessment phase in an LCC, because all inventory data comprise a single unit of measure, namely currency. Thus, there is no need for characterization or weighting of inventory data. Aggregate cost data provide a direct measure of financial impact. Procedures for interpretation, communication, and review are analogous to those for an LCA.

\section{Example}

A detailed automobile case study was developed to illustrate methodological choices an analyst would face in applying the code of practice. The case study considered purchase of an automobile by a consumer, selection of a model for new product development by a manufacturer, and purchase of an automobile by a municipal fleet manager. The study showed that a consumer would be challenged to develop a consistent and accurate inventory to support their purchase decision. The manufacturer would most likely be in the best position to conduct a meaningful LCC. Even this relatively simple case study indicated the challenges faced in attempting to monetize environmental impacts. The case study highlights that there has been limited consideration of the relevant decision makers, their respective criteria for success, and other exogenous contextual factors that constrain them from taking a lifecycle perspective (Cole and Sterner 2000). In many cases, costs are isolated across the various life-cycle stages and addressed in fragmented ways. New business models and innovative collaborations may be required to develop more integrated systems to effectively capture potential benefits identified in a LCC study.

\section{Next steps}

The code of practice takes a critical first step in outlining a rigorous methodological approach for LCC. It will be important to apply these guidelines to additional case studies to gain experience and validate the utility of the method across different industry sectors. Some experimentation is required to show how complementary LCC and LCA 
Table 1 Chronicle of the SETAC task force LCC code of conduct (2006-2011)

\begin{tabular}{|c|c|c|}
\hline & City, occasion & Purpose \\
\hline 1 & The Hague, SETAC Europe Annual Meeting, May 6, 2006 & $\begin{array}{l}\text { Kickoff Meeting SETAC LCC Task Force } \\
\text { (LCC Code of Practice) }\end{array}$ \\
\hline 2 & $\begin{array}{l}\text { Stuttgart, SETAC Europe LCA Case Studies Symposium, } \\
\text { December 6, } 2006\end{array}$ & $\begin{array}{l}\text { Discussion meeting; ten writing members had been } \\
\text { appointed meanwhile }\end{array}$ \\
\hline 3 & Porto, SETAC Europe Annual Meeting, May 18/20, 2007 & First draft chapters discussed \\
\hline 4 & Zürich, LCM Conference, August 26, 2007 & Working meeting; assignment of further writing duties \\
\hline 5 & Sydney, SETAC World Congress, August 6, 2008 & $\begin{array}{l}\text { Presentation and discussion of intermediate results of the } \\
\text { LCC Code of Practice (Platform presentations as part of } \\
\text { the Life Cycle Section of the congress) }\end{array}$ \\
\hline 6 & 2009-2010 no further meetings & $\begin{array}{l}\text { Draft writing, final draft, peer reviews, comments by Mary Ann } \\
\text { Curran, Jim Fava (foreword) and others; editing, final review, } \\
\text { and preparation of publication }\end{array}$ \\
\hline 7 & March 2011 & Published by SETAC Press, Pensacola, FL \\
\hline
\end{tabular}

${ }^{a}$ The LCC book (David Hunkeler, Kerstin Lichtenvort and Gerald Rebitzer eds.), resulting from the first SETAC LCC Working Group (2002-2005), had just appeared and was on sale in Sydney (SETAC bookshop)

studies can effectively inform decision making of multiple stakeholders with differing and potentially conflicting perspectives and goals. LCC has been promoted as one of three pillars of sustainability. There is also a need to explore how separate assessment of the environmental, economic, and social pillars can be used in practice by decision makers to make trade-offs explicit. The ultimate goal is to build consensus for an international standard parallel to the ISO 14040 standard. This would put LCC on a solid basis, and lay the foundation for eventual integration of social LCA into a comprehensive three-pillar product LCSA.

Life-cycle costing: a Code of Practice (98 pp.), is published by SETAC Press and is available at https:// www.setac.net/setacssa/ecssashop.show_product_detail? p_mode $=$ detail\&p_product_serno $=374$ for $\$ 5$ for members and $\$ 12$ for non-members. It is based on the deliberations of the SETAC Working Group on Life-Cycle Costing. A short chronicle of the activities of this working group, officially named "SETAC Task Force Environmental Life Cycle Costing: Code of Practice", is found above (Table 1).

\section{References}

Blanchard B (1978) Design and manage to life cycle cost. M/A Press, Portland
Ciroth A (2009) Cost data quality considerations for eco-efficiency measures. Ecol Econ 68(6):1583-1590

Cole RJ, Sterner E (2000) Reconciling theory and practice of life-cycle costing. Build Res Inf 28(5/6):368-375

Curran MA (2007) Co- product and input allocation approaches for creating life cycle inventory data: a literature review. Int J Life Cycle Assess 12(Special Issue 1):65-78

Howarth RB (1996) Discount rates and sustainable development. Ecol Model 92:263-270

Hunkeler D, Rebitzer G (2003) Life cycle costing: paving the road to sustainable development? Int J Life Cycle Assess 8(2):109-110

Hunkeler D, Lichtenvort K, Rebitzer G (eds.) (2008) Environmental life cycle costing. SETAC, Pensacola, FL (US) in collaboration with CRC Press, Boca Raton, FL, USA

ISO (International Standards Organization) (2006a) International standard ISO 14040: environmental management-life cycle assessment-principles and framework. Geneva $(\mathrm{CH})$

ISO (International Standards Organization) (2006b) International standard ISO 14044: environmental management-life cycle assessment-requirements and guidelines. Geneva $(\mathrm{CH})$

Klöpffer W (2008) Life cycle sustainability assessment of products. Int J Life Cycle Assess 13(2):89-94

Norris GA (2001) Integrating life cycle cost analysis and LCA. Int J Life Cycle Assess 6(2):118-120

Schaltegger S, Burrit R (2000) Contemporary environmental accounting: issues, concepts, and practice. Greenleaf, Sheffield

Swarr TE, Hunkeler D, Klöpffer W, Pesonen H-L, Ciroth A, Brent AC, Pagan R (2011) Environmental life cycle costing: a code of practice. Society of Environmental Chemistry and Toxicology (SETAC), Pensacola

UNEP (United Nations Environmental Programme) (2009) Guidelines for social life cycle assessment of products. Paris, France 